\title{
Avaliação do conhecimento em saúde bucal dos profissionais de Unidade de Saúde da Família.
}

\author{
$\underline{\text { Daiana Arcanjo Silva }^{1} \text {; Ana Aúrea Alécio Oliveira Rodrigues }}{ }^{2}$
}

1. Bolsista PIBIC/CNPq, Graduanda em Odontologia, Universidade Estadual de Feira de Santana, e-mail: daianaarcanjo@hotmail.com

2. Orientadora, Departamento de Saúde, Universidade Estadual de Feira de Santana, e-mail: alecio@uefs.br

\section{Introdução}

Palavras-chave: conhecimento; saúde bucal; trabalho interdisciplinar

A inclusão da Equipe de Saúde Bucal (ESB) na Estratégia de Saúde da Família, em 2001, é um dos grandes avanços na perspectiva da integralidade da atenção, embora não faça parte da equipe mínima, pois é considerada uma equipe auxiliar. Por sua vez, Gallarreta (2008) e colaboradores, afirmam que a saúde bucal e geral não podem ser desvinculadas. Considerando a necessidade de um cuidado integral, faz-se necessário que os profissionais das EqSF realizem suas ações de forma interdisciplinar e procurem se articular para o planejamento das ações e da assistência. A saúde bucal tem importância na qualidade de vida das pessoas e as doenças bucais podem se refletir nas condições sistêmicas, como também algumas doenças sistêmicas podem ter sinais na cavidade bucal e é importante que os profissionais de saúde, não apenas o $C D$, reconheça essas manifestações para o tratamento adequado ou o encaminhamento devido.

A busca por trabalhos referentes ao conhecimento da equipe de saúde da família sobre saúde bucal, foi realizada nas bases de dados do site bireme.br, scielo, google escolar e capes. E poucos trabalhos foram encontrados. Desta forma, levando-se em consideração a importância do trabalho multidisciplinar entre os profissionais da Equipe de Saúde da Família, e a ausência de estudos mais aprofundados, esse estudo tem por objetivo avaliar o conhecimento sobre saúde bucal dos profissionais da USF de Nordestina/BA.

\section{Materiais e métodos}

Os participantes das pesquisas são os profissionais de saúde (exceto o cirurgião dentista) que trabalham em três das USF de Nordestina. Foram selecionadas intencionalmente duas da zona rural e uma urbana. Como instrumento para coleta de dados foram realizadas entrevistas semiestruturadas com perguntas voltadas para o conhecimento sobre saúde bucal.

\section{Instrumentos de coleta de dados:}

A entrevista foi semiestruturada, por ser, um instrumento adequado para uma pesquisa qualitativa. Na entrevista semiestruturada, o investigador tem uma lista de questões para serem respondidas. Sendo a entrevista flexível (MATTOS, 2005).

\section{Análise dos dados}

Para desenvolver o presente trabalho, optou-se pela análise de conteúdo temática. Segundo Minayo (2007), a análise de dados temática se faz em três etapas: pré-análise, exploração do material ou codificação, e tratamento dos resultados obtidos. 
Na pré-analise desse estudo, as falas obtidas nas entrevistas foram transcritas de forma fiel a gravação obtida. Sendo possível identificar os pontos em comum entre os participantes, as questões que convergiam, divergiam, e possíveis pressupostos puderam ser levantados. Na exploração do material, dentro das categorias estabelecidas foram assinaladas as falas que transmitiam acontecimentos de maior relevância, a respeito de cada tema. Na última etapa, o conteúdo obtido foi classificado e agregado em dados. E diante disso os pressupostos foram confrontados com os resultados obtidos, e em seguida realizou-se a discussão.

\section{Resultados e discussão}

\section{Compreensão da doença cárie como doença de saúde pública.}

Todos os entrevistados apontam a cárie como o principal problema que acomete a cavidade bucal. A maioria associou a cárie com a má escovação, como podemos notar nas seguintes falas:

"Cárie é um desgaste no dente decorrente de um modo errado, que as pessoas comem ou não escovam o dente" (MÉDICO 3).

Outro fator notado na entrevista é que a dieta rica em açúcares contribuiria para a incidência de cárie. Em nossos estudos, todos os entrevistados concordam que cárie é uma doença. Conforme Andrade et. al (2016) 96,8\% dos profissionais em estudo realizado percebem a cárie dentária como uma doença, que surge pela falta de higiene e dieta inadequada (rica em doces).

\section{Invisibilidade da doença periodontal}

A maioria dos entrevistados disseram saber o que seria a doença periodontal, e como exemplo citavam a gengivite, como se pode notar nas seguintes falas:

"A gengivite, tem pessoa que tem sangramento, tem aquela que chama piorreia que amolece o dente, geralmente o pessoal de idade tem muito" (AC'S2).

Porém, uma quantidade significante dos entrevistados, disseram não saber o que era, ou não sabiam explicar. Outro ponto observado, foi a errônea associação de doença periodontal ao câncer bucal.

A periodontite se manifesta pela perda de inserção progressiva, com a destruição do ligamento periodontal e suporte ósseo alveolar. A progressão da doença periodontal envolve um conjunto de eventos inflamatórios e imunológicos (LINDHE, 2005).

Ao serem perguntados sobre a relação entre doenças sistêmicas e doenças na cavidade bucal, uma parcela dos entrevistados disse não acreditar que exista uma relação entre doenças sistêmicas e doenças bucais, ou até que seria o contrário. Nota-se em:

"Na verdade, eu creio que o contrário seria mais válido. A cárie e outras doenças orais afetam as doenças sistêmicas, como a endocardite bacteriana que pode ser ocasionada através de um abcesso dentário, tá certo?! Não o contrário" (MÉDICO1). 
$\mathrm{Na}$ literatura existem trabalhos que comprovam a associação de doenças bucais e doenças sistêmicas. Como por exemplo a existência de relação entre periodontite e a doença cardíaca coronária/aterosclerose (MATILLA et al. 1995, BECK et al, 1996).

\section{Relação sistêmica com as doenças bucais}

NARVAI (2001), traz que boca não deve ser tratada isoladamente, pois a saúde bucal é de grande importância para o organismo. Tendo a boca uma intima comunicação com todo o sistema, e sendo esta afetada, qualquer tipo de deficiência pode afetar outros órgãos também.

A maioria dos entrevistados acreditam que doenças sistêmicas podem afetar diretamente a cavidade oral. Dentre as doenças mais citadas estão: Diabetes, doenças gastrointestinais e problemas neurológicos e mentais.

Segundo Albandar (2002), a diabetes se apresenta como um dos principais fatores de risco relacionados a doença periodontal, podendo influenciar no processo da doença e em sua prevalência.

Outras doenças também foram citadas como: câncer e alcoolismo.

\section{Educação permanente}

A maioria dos entrevistados declararam não ter recebido nenhum tipo de capacitação voltada para a saúde bucal. Em relação a realização de atividades de educação permanente voltadas para os profissionais das equipes, alguns entrevistados confundiram educação permanente com atividades de educação em saúde desenvolvidas para os usuários.

“Aqui no PSF não, e acredito que nenhum tenha” (MÉDICO3).

"A gente tem esse treinamento sim. Eles "mostra" vídeo, e... e fala como pode ficar a saúde da pessoa se não tiver um bom tratamento bucal, né. Mas, profundo assim mesmo, treinamento a gente não teve, só palestra mesmo" (ACS1).

\section{Trabalho em equipe}

A maioria dos profissionais entrevistados julgaram existir sim trabalho em conjunto com todos os profissionais voltados para a saúde bucal. Muitos citaram o Programa Saúde na Escola (PSE) como trabalho em equipe. O PSE realiza ações de promoção, prevenção e atenção à saúde, para crianças e jovens da rede pública de ensino (Ministério da Educação, 2016).

"Tem alguns trabalhos, por exemplo o trabalho do PSE, toda a ação, toda ação atividade fora da unidade de saúde os dentistas eles sempre estão. Por exemplo tem algum dia da mulher, outubro rosa, sempre tem uma "standizinha", e eles trabalham avaliando a cavidade oral desses pacientes que vão aparecer" (ENF2).

Outra parcela não soube responder ou disse não existir.

Na USF, o trabalho em equipe multiprofissional é um dos pilares para um novo modelo de assistência à saúde. Na qual há relação recíproca entre as múltiplas intervenções técnicas e a interação entre diferentes áreas profissionais (JACOWSKI et al, 2016). 


\section{Considerações finais}

O PSF é a porta de entrada para o Sistema Único de Saúde (SUS). Portanto, é de fundamental importância que os profissionais dos PSF, estejam capacitados para perceber as necessidades odontológicas desses pacientes. Pois a saúde bucal deve ser objeto de atenção não somente do cirurgião dentista, e sim de todos os profissionais da USF. Assim, podendo orienta-los, e encaminha-los para o atendimento de suas carências.

Uma parcela importante da população brasileira não tem acesso a serviços odontológicos. Peres (2012), relata que aproximadamente metade da população analisada disse sentir necessidade de tratamento odontológico no último ano e, desta, aproximadamente $15 \%$ não conseguiram atendimento. Os resultados mostram que o conhecimento das equipes ainda é incipiente. Sendo essencial a elaboração de programas e ações, que visem a Educação permanente em Saúde bucal e promoção, voltados para todos os profissionais das Unidades de Saúde da Família.

\section{Referências}

ANDRADE, P. H. A. et al. Conhecimento de Médicos e Enfermeiros Sobre

Saúde Bucal na Primeira Infância. Revista Brasileira de Ciências da Saúde. Paraíba, 2016.

GAlARRETA, F. W. M. TURSSI, C. P. DIBB, R. G. P. SERRA, M. C. Histórico de: atenção a condições sistêmicas e suas implicações, sobretudo nos fatores de risco de cárie. Rev. odonto ciênc. Ribeirão Preto, 2008.

GLÓRIA, Víviann. Relação entre condições bucais e a saúde geral. 29f. Dissertação (especialização) - Departamento de saúde, Universidade Federal de Minas Gerias, 2011.

JACOWSKI, M. et al. Trabalho em equipe: percepção dos profissionais da estratégia de saúde da família. Revista Baiana de Enfermagem. Salvador, 2016.

LINDHE, J. KARRING, T. LANG, N. P. Tratado de Perídontia Clínica e Implantologia Oral. 4. ed. Guanabara Koogan. Rio de Janeiro, 2005.

MATILLA, K. J. VALTONEN, V.V., NIEMINEN, M. \& HUTTUNEN, J.K., (1995). Dental infection and the riskof new coronary events prospective study of patients with documented coronary artery disease. Clinical Infectious Disease 20, 588- 592.

MATTOS, P. LINCOLN, C. L.: A entrevista não-estruturada como forma de conversação: razões e sugestões para sua análise. Rev. adm. publica; 39(4):823-847, jul.- ago. 2005.

MINAYO, M. C. S. O Desafio do Conhecimento: Pesquisa Qualitativa em Saúde. 10. ed. São Paulo: HUCITEC, 2007. 406 p.

NARVAI, P. C. Odontologia e saúde bucal. São Paulo, Hucitec, 2001.

PERES, M. A. et al. Desigualdades no acesso e na utilização de serviços odontológicos no Brasil: análise do Sistema de Vigilância de Fatores de Risco e Proteção para Doenças Crônicas por Inquérito Telefônico. Cad. Saúde Pública. Rio de Janeiro, 2012. 